\title{
Prospective double-blind comparison of buprenorphine and pethidine in ureteric colic
}

\author{
I G FINLAY， R SCOTT, C S MCARDLE
}

\begin{abstract}
In a double-blind prospective trial 26 consecutive patients with proved ureteric colic were allocated at random to receive $100 \mathrm{mg}$ pethidine or $0.3 \mathrm{mg}$ buprenorphine by intramuscular injection. Pain relief was assessed by standard linear analogue and ordered categories scales. The mean pain relief on the linear analogue scale was $3.80 \pm S E M \quad 0.64$ in patients receiving pethidine and $6.86 \pm 0.40$ in those receiving buprenorphine $(p<0.001)$. The corresponding values for mean pain relief in the ordered categories scale was $1 \cdot 78 \pm 0.26 \quad \mathbf{2} \cdot 76 \pm 0.20$ $(\mathbf{p}<\mathbf{0 . 0 1})$.
\end{abstract}

These observations suggest that buprenorphine is superior to pethidine as analgesia in ureteric colic.

\section{Introduction}

Ureteric colic is a common, recurrent, and excruciatingly painful clinical entity. ${ }^{12}$ Opiate derivatives, the accepted analgesic treatment, have a high potential for addiction, yet often fail to alleviate pain despite multiple administrations. ${ }^{3}$ Early reports suggest that buprenorphine possesses qualities that may be of benefit in ureteric colic. Buprenorphine is a synthetic analgesic agent derived from thebaine and closely related in structure to morphine; it is potent with a longer duration of action than either pethidine or morphine ${ }^{4}$ and is superior to the conventional opiate analgesics for postoperative pain. ${ }^{5}$ Moreover, chronic administration to animals and recently to human volunteers has not produced physical dependence. ${ }^{6}$

We report the results of a study comparing the use of buprenorphine and pethidine in the management of ureteric colic.

\section{Patients and methods}

Thirty-six consecutive patients in whom ureteric colic was diagnosed on the basis of signs and symptoms and who had not previously received analgesia were included in the study. These patients were allocated at random to receive from identical numbered and coded ampoules either buprenorphine $(0.3 \mathrm{mg})$ or pethidine $(100 \mathrm{mg})$ by intramuscular injection. The subsequent medical care was standardised and included intravenous fluids for a minimum of 24 hours and bed rest. Further analgesia of $100 \mathrm{mg}$ pethidine was given by intramuscular injection on demand.

Intravenous pyelography was performed on all patients within 24 hours of admission. The $x$-ray films were interpreted independently by a consultant urologist (RS). In 26 patients ureteric calculi were unequivocally identified radiologically. The remaining 10 patients, in whom a stone could not be seen on $x$-ray, were excluded from the study. Pain was assessed 12 hours after admission by a standard $10 \mathrm{~cm}$ linear analogue scale. ${ }^{7}$ Patients were instructed that the left-hand end represented no pain while the right-hand end represented the worst pain imaginable. They were then asked to draw perpendicular lines through the horizontal axis to represent the degree of pain before

\section{Royal Infirmary, Glasgow G4 OSF}

I G FINLAY, BSC, FRCS, research fellow, university department of surgery R SCOTT, FRCSGLAS, FRCSED, consultant urologist

C S MCARDLE, MD, FRCS, consultant surgeon, university department of surgery administration of analgesia and a second line indicating the maximal pain relief after injection of the drug.

Similar measurements were made using an ordered categories scale (no pain $=0$; mild pain $=1$; moderate pain $=2$; severe pain $=3$; very severe pain $=4)$. The duration of pain relief was determined by the patient's demand for further analgesia and is expressed as the mean number of hours free of pain in the first 12 hours after admission.

The degree of sedation was assessed by the nursing staff in attendance using an ordered categories scale (no sedation $=0$; mild sedation drowsiness $=1$; asleep $=2$ ). Other side effects were also carefully recorded.

Comparison of the results of pain scores between the groups was undertaken using an unpaired Student's $t$ test. The duration of action was analysed using a Mann-Whitney unpaired test, while comparison of the number of patients achieving complete pain relief was performed using a Fisher's exact test.

\section{Results}

Of the 26 patients included in the study, 13 received pethidine (group 1) and 13 buprenorphine (group 2). There was no significant difference between the groups for age, height, and weight (table I). The degree of initial pain was comparable in both groups as assessed by the linear analogue and ordered categories scales (table II). The mean pain relief by the analogue scale was $3.8 \pm$ SEM 0.6 in group 1 and $6.8 \pm 0.4$ in group 2 (table $I ; p<0.001$ ). The mean pain relief in the ordered categories scale was $1.78 \pm 0.2$ in group 1 and $2.76 \pm 0.2$ in group $2(\mathrm{p}<0.01)$.

TABLE I-Mean age, height, and weight of patients allocated to the pethidine and buprenorphine groups and ratio of men to women. Results are mean $+S D$

\begin{tabular}{lcc}
\hline & $\begin{array}{c}\text { Group 1 } \\
\text { (pethidine) }\end{array}$ & $\begin{array}{c}\text { Group 2 } \\
\text { (buprenorphine) }\end{array}$ \\
\hline Age (years) & $42 \cdot 6 \pm 13 \cdot 7$ & $40 \cdot 5 \pm 15 \cdot 4$ \\
Height (cm) & $170 \cdot 9 \pm 11 \cdot 7$ & $174 \cdot 4 \pm 5 \cdot 3$ \\
Weight (kg) & $74 \cdot 1 \pm 17 \cdot 9$ & $79 \cdot 7 \pm 12 \cdot 3$ \\
Ratio of men to women & $10: 3$ & $12: 1$ \\
\hline
\end{tabular}

TABLE II-Comparison of pain before and after injection. Results are mean $\pm S E$

\begin{tabular}{lcc}
\hline & $\begin{array}{c}\text { Group 1 } \\
\text { (pethidine) }\end{array}$ & $\begin{array}{c}\text { Group 2 } \\
\text { (buprenorphine) }\end{array}$ \\
\hline $\begin{array}{l}\text { Linear analogue scale } \\
\text { (range 0-10): }\end{array}$ & & \\
$\quad$ Initial pain & & \\
$\quad$ Pain after injection & $7.96 \pm 0.36$ & $8.02 \pm 0.28$ \\
Ordered category scale & $4 \cdot 16 \pm 0.28$ & $1 \cdot 16 \pm 0.12$ \\
$\quad$ (range 0-4): & & \\
$\quad$ Initial pain & & \\
Pain after injection & $3.64 \pm 0.19$ & $3.39 \pm 0.11$ \\
\hline
\end{tabular}

In group 1 the mean period free of pain within the first 12 hours of admission was $4.47+1.0$ hours compared with $9.02+0.9$ hours in group $2(p<0.01)$. Only one of 13 patients in group 1 required only a single administration of analgesia compared with six of the 13 patients in group $2(p<0.04)$. Significantly more sedation was achieved with buprenorphine $(0.31$ in group $1,1.81$ in group $2 ; \mathrm{p}<0.005)$. Nausea and vomiting occurred in two patients in each group, though it was more severe in the patients who had received buprenorphine. One patient in group 2 developed transient diplopia.

Three patients from each group required surgical removal of the calculus; all six patients required multiple administrations of analgesia. The remaining 20 patients passed their stones spontaneously. 


\section{Discussion}

Urinary tract calculi are common and there is some evidence that the incidence of symptomatic stones is increasing. ${ }^{8}$ In a random sample of 3398 patients in an urban population in Scotland the prevalence of upper urinary tract calculi was $3.5 \% .{ }^{9}$ It has been estimated that $12 \%$ of males will suffer from at least one episode of ureteric colic secondary to stones during their lifetime ${ }^{8}$ and half these patients will have at least one recurrence within five years. " The severe pain associated with ureteric colic necessitates the use of potent analgesics such as opiates or their derivatives. Confirmed narcotic addicts exploit this need by simulating the signs and symptoms of ureteric colic in an effort to gain access to opiates. Furthermore, the repeated use of these drugs may lead to physical dependence in non-addicts. There is therefore a need for potent, non-dependent analgesic agents.

The ideal analgesic in ureteric colic should provide excellent pain relief, a long duration of action, no side effects, and some smooth-muscle relaxation. In this study buprenorphine provided significantly improved pain relief, a longer duration of action, and better sedation than pethidine. Complications associated with both drugs were few: nausea and vomiting have been attributed to buprenorphine in other studies but occurred equally in both groups of patients in this study.

That fewer patients receiving buprenorphine required further analgesia may suggest that buprenorphine possesses a pharmacological action other than that of pure analgesia. It produces mild smooth-muscle contraction and recent studies in animals suggest that this may promote the passage of small calculi.. ${ }^{11}$ Despite five years of clinical use it shows little or no potential for addiction, and our results suggest that it may be a realistic alternative to the traditional opiates in patients with ureteric colic. It must be remembered, however, that clinicians can assess the addiction potential of any drug only after several years of wide experience.

\section{References}

${ }^{1}$ Scott R, Freeland R, Mowat W, et al. The prevalence of calcified upper urinary tract stone disease in a random population. Br $\mathcal{F}$ Urol 1977;49: 589-95.

2 Anonymous. Recurrent renal calculi. $B r$ Med f 1981 ;282:5.

${ }^{3}$ Walsh A. Renal colic. Br f Hosp Med 1978;19:224-6.

Lewis JW. Ring C-bridged derivatives of thebaine and oripavine. $A d v$ Biochem Psychopharmacol 1974;8:123-36.

5 Downing JW, Leary WP, White ES. Buprenorphine: a new potent long acting synthetic analgesic. Comparison with morphine. $\mathrm{Br} \mathcal{F}$ Anaesth $1977 ; 49: 251-4$

${ }^{6}$ Jasinski DR, Pevnick JS, Griffith JD. Human pharmacology and abuse potential of the analgesic buprenorphine: a potential agent for treating narcotic addiction. Arch Gen Psychiatry 1978;35:501-16.

7 Huskisson EC. Measurement of pain. Lancet 1974;ii:1127.

${ }^{8}$ Sierakowski R, Finlayson B, Landes RR, Finlayson CD, Sierakowski N. The frequency of urolithiasis in hospital discharge diagnosis in the United States. Invest Urol 1978;15:438-41.

${ }^{9}$ Scott R, Freeland R, Mowat W. The prevalence of renal stones in a random population and volunteer population. In: Brockis JS, Finlayson B, eds. Urinary calculus. Littleton, Mass, USA: PSG, 1981.

${ }^{10}$ Ljunghall S, Backman V, Danielson BG, et al. Long term treatment with Bendrofluromethiazide for prevention of renal stones. In: Smith $\mathrm{LH}$ Robertson WG, Finlayson B, eds. Urolithiasis: clinical and basic research. New York and London: Plenum Press, 1981.

11 Watson GS, Edmond P. Analgesics and ureteral function. In: Harcus AW, Smith R, Whittle B, eds. Pain. Edinburgh: Churchill Livingstone, 1977 : 27-33.

(Accepted 16 April 1982)

\title{
Hypnotherapy for incontinence caused by the unstable detrusor
}

\author{
R M FREEMAN, K BAXBY
}

\begin{abstract}
Fifty incontinent women with proved detrusor instability completed 12 sessions of hypnosis (symptom removal by direct suggestion and "ego strengthening") over one month. This was continued at home with a prerecorded cassette, and all patients were followed up for at least six months. At the end of the 12 sessions 29 patients were entirely symptom free, 14 improved, and seven unchanged. Three months later cystometry in 44 of the patients showed conversion of the cystometrogram to stability in 22 and a significant improvement in a further 16; only six showed no objective improvement. Seven patients relapsed (three after bereavement). Further treatment was given and five out of six patients were rendered symptom free again. Patients with detrusor instability were not found to have a noticeably increased susceptibility to hypnosis.
\end{abstract}

It is concluded that psychological factors are very important in "idiopathic" detrusor instability and that

Department of Urology, Royal Infirmary, Dundee DD1 9ND

R M FREEMAN, $M B$, CHB, senior house officer (now registrar, departments of obstetrics and gynaecology, St Helier Hospital, Carshalton, Surrey, and St George's Hospital, London SW 17)

$\mathrm{K}$ BAXBY, BSC, FRCS, consultant urological surgeon hypnotherapy is effective for incontinence due to this disorder.

\section{Int roduction}

Urinary incontinence is one of the most socially incapacitating problems for many women today. It is now known to be more prevalent than was previously thought. ${ }^{1}$ A common cause of incontinence is an unstable detrusor (detrusor instability). In this condition a person lacks the ability to inhibit detrusor contractions during bladder filling. Detrusor instability usually produces symptoms of frequency, urgency, and urge incontinence. The exact prevalence of the condition is uncertain but it is probably present in about half of all women presenting with urinary incontinence.

The view that uninhibited detrusor contractions cause incontinence is not new, ${ }^{34}$ but with the advent of urodynamic investigations the diagnosis has become easier to confirm and detrusor instability has become a clinical entity in its own right. The aetiology of the condition remains obscure. Apart from outflow obstruction (more common in men) and neurological disease (for example, multiple sclerosis), in the vast majority of cases no cause can be found. It is therefore not surprising that treatment often fails. Apart from bladder retraining (see below) there is nothing which will reliably convert instability to stability. One hypothesis is that the condition is psycho- 